\title{
Increased expression of TAZ and associated upregulation of PD-L1 in cervical cancer
}

\author{
Yanyan $\operatorname{Han}^{1 *} \mathbb{C}$, Dandan Liu² and Lianhong Li
}

\begin{abstract}
Background: As an important component of the Hippo pathway, WW domain-containing transcription regulator 1 (TAZ), is a transcriptional coactivator that is responsible for the progression of various types of cancers. Programmed cell death protein 1 (PD-1) receptors in activated T cells and their ligand programming death force 1 (PD-L1) are the main checkpoint signals that control T cell activity. Studies have shown high levels of PD-L1 in various cancers and that PD-L1/PD-1 signals to evade T-cell immunity. Recent data have demonstrated that TAZ can regulate the characteristics of cancer cells via PD-L1. Cervical cancer is a common gynecological disease worldwide. In this study, we attempted to evaluate the effects of TAZ and PD-L1 on cervical cancer.

Methods: Hela cervical cancer cells were transfected with TAZ plasmid or TAZ siRNA or PD-L1 siRNA by using Lipofectamine 2000. The relationship between TAZ and PD-L1 in cervical cancer cells was determined by qRT-PCR and western blotting. The functional roles of TAZ were confirmed via CCK-8, Transwell and flow cytometry assays. Western blotting was utilized to observe the expression of BCL-2 and Caspase-3. The clinicopathological correlation of TAZ and PD-L1 was evaluated via relevant databases.

Result: TAZ is upregulated in cervical cancer and induces the growth and metastasis of cervical cancer cells by targeting PD-L1and inhibiting the ratio of apoptotic of cancer cells. High TAZ and PD-L1 expression was observed in different stage, grade, histological patterns, and ages of cervical cancer groups compared with normal cervix groups. Furthermore, high TAZ expression was positively correlated with the infiltration levels of immune cells and the expression of PD-L1.
\end{abstract}

Keywords: TAZ, PD-L1, Cervical cancer

\section{Introduction}

Cervical cancer $(\mathrm{CC})$ is the second most common cancer among women in the worldwide and it has a high mortality rate [1]. Although significant achievements have been made in CC therapy, its prognosis of it is still poor due to the high metastasis and recurrence [2]. Thus, it is necessary to find new treatment methods and molecular mechanisms for CC.

\footnotetext{
*Correspondence: pt9m7rj8@s.okayama-u.ac.jp

${ }^{1}$ Department of Pathology, Okayama University Graduate School

of Medicine, Dentistry, and Pharmaceutical Sciences, 2-5-1, Shikata-cho, Kita-ku, Okayama 700-8558, Japan

Full list of author information is available at the end of the article
}

As an evolutionary preservation pathway, the Hippo signaling pathway can control the size of organs and regulate cell proliferation, self-renewal, differentiation, and survival [3]. Moreover, Hippo signaling can have two important roles, tumor-suppressive and oncogenic activities, in different tumors [4]. WW domain-containing transcription regulator 1 (TAZ) is a downstream nuclear effector in the Hippo pathway that induces the proliferation and inhibits the apoptosis of cancer cells $[5,6]$. A large number of studies have shown that high expression of TAZ can cause Epithelial-mesenchymal transition (EMT), inhibit apoptosis of cancer cells, and increase the number of cancer stem cells in vitro [7, 8]. Knockdown of TAZ expression can have a negative effect

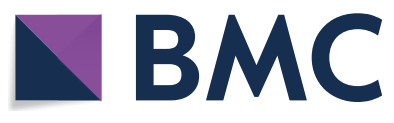

(c) The Author(s) 2021. Open Access This article is licensed under a Creative Commons Attribution 4.0 International License, which permits use, sharing, adaptation, distribution and reproduction in any medium or format, as long as you give appropriate credit to the original author(s) and the source, provide a link to the Creative Commons licence, and indicate if changes were made. The images or other third party material in this article are included in the article's Creative Commons licence, unless indicated otherwise in a credit line to the material. If material is not included in the article's Creative Commons licence and your intended use is not permitted by statutory regulation or exceeds the permitted use, you will need to obtain permission directly from the copyright holder. To view a copy of this licence, visit http://creativecommons.org/licenses/by/4.0/. The Creative Commons Public Domain Dedication waiver (http://creativeco mmons.org/publicdomain/zero/1.0/) applies to the data made available in this article, unless otherwise stated in a credit line to the data. 
on the migration, invasion, and tumorigenesis of cancer cells in nude mice $[9,10]$. Nevertheless, little research has focused on the role of TAZ in the Hippo pathway in CC. In previous studies, TAZ levels were observed to increase in cervical cancer and its microenvironments [11]. However, the precise mechanism of this process in CC cells remains uncertain.

The PD-1/PD-L1 axis immune checkpoint pathway can induce immune evasion of cancer cells and thus inhibit the immune response in various solid tumors, including CC [12]. Overexpression of PD-L1 has been found in human CC $[13,14]$. PD-L1 can not only mediate T cell suppression but also promote cancer cell growth and invasion [15]. Early studies have indicated that the Hippo pathway can affect the immune response to cancer and the recruitment and activation of immune cells $[16,17]$. The upstream factors mammalian STE20-like kinase 1 and $2($ MST1/2) and large tumor suppressor 1 and 2 (LATS1/2) can inhibit PD-L1 expression, while TAZ and YAP induce high expression of PD-L1 in breast and lung cancer cell lines [18]. Comparison results indicate that TAZ activity can affect PD-L1 expression in cancer cell lines and that the TAZ/YAP/TEAD pathway increases PD-L1 promoter activity [18]. However, no research has demonstrated the correlation of TAZ and PD-L1 in CC and their effects on the tumor characteristics of CC.

Therefore, it is important to evaluate the effects of TAZ and PD-L1 on CC. We showed that TAZ is upregulated and can regulate cell proliferation, invasion, apoptosis, and clinical significance through PD-L1 in the CC in our study. Additionally, significant correlation between TAZ expression and the infiltration levels of immune cells and the expression of PD-L1 were observed in this research.

\section{Materials and methods}

\section{Cell culture}

The cervical cancer cell line HeLa (ACC, USA) was maintained in minimal essential medium (MEM) (HyClone ${ }^{\mathrm{TM}}$; Thermo Fisher Scientific, Inc., Waltham, MA, USA) supplemented with $10 \%$ fetal bovine serum (FBS) $\left(\right.$ HyClone $^{\mathrm{TM}}$ ) at $37^{\circ} \mathrm{C}$ in a humidified atmosphere of $95 \%$ air and $5 \% \mathrm{CO}_{2}$.

\section{Cell transfection}

At $24 \mathrm{~h}$ prior to transfection, HeLa cells were plated into 6-well plates at a density of $5 \times 10^{5}$ per well and were then transfected with 100 pmol of TAZ siRNA or nonspecific sequence control (NC) using Lipofectamine 2000 (Invitrogen, USA) according to the manufacturer's protocol. PD-L1 siRNA was transfected in a similar manner. The untransfected HeLa cells were also a negative control.

The coding sequence (CDS) of the human TAZ gene was amplified from the cDNA of the cervical cancer cell line $\mathrm{SiHa}$ by polymerase chain reaction (PCR) using the following primers:

TAZ-F: CCCAAGCTTATGCCTCTGCACGTGAAG HindIII.

TAZ-R: CCGGAATTCTCTCCCAGGCTGGAGGTG EcoRI.

A pcDNA3 eukaryotic expression vector (Invitrogen, San Diego, CA, USA) was used to establish stably transfect cells overexpressing TAZ. To construct pcDNA3TAZ, the full-length human TAZ gene $\mathrm{pB} 4$ was digested with EcoRI and then inserted into an EcoRIcleaved pcDNA3 vector. Cells were transfected with pcDNA3 or pcDNA3-TAZ using the lipofection technique according to the manufacturer's protocol (Gibco BRL, Life Technologies, Rockville, MD, USA).

\section{Quantitative real-time polymerase chain reaction (RT-qPCR)}

Total RNA was extracted using TRIzol ${ }^{\circledR}$ (Transgene, China) from parental and transfected HeLa cells, followed by isopropanol precipitation and chloroform extraction. cDNA was synthesized using the Reverse Transcriptase system (Invitrogen; Thermo Fisher Scientific, Inc.), in accordance with the manufacturer's protocol. RT-PCR was performed using an $\mathrm{iCycler}^{\mathrm{TM}}$ Real Time system (Bio-Rad Laboratories, Richmond, CA, USA) using the SYBR Premix EX Tag Master mixture kit (Takara Bio, Inc.) according to the manufacturer's protocol. The quantification of gene transcription was normalized to GAPDH mRNA. The primers used in this study were as follows:

TAZ: Primer F $5^{\prime}$ TCATCACCGTGTCCAATC $3^{\prime}$. Primer R $5^{\prime}$ CTGAAGAAGTGGgAGTGTAG $3^{\prime}$. GAPDH: Primer F $5^{\prime}$ CACCCACTCCTCCACCTT TG $3^{\prime}$.

Primer R 5' CCACCACCCTGTTGCTGTAG 3'.

The samples were amplified in different wells and run in triplicate. The relative expression of genes was compared with the $2^{-\Delta \Delta \mathrm{Ct}}$ relative quantification method.

\section{CCK-8 assay}

The effects of TAZ on HeLa cell proliferation were measured by Cell Counting Kit-8 (CCK-8) (SigmaAldrich, USA). HeLa cells were plated at a density of $5 \times 10^{3}$ cells per well in 96 -well plates $24 \mathrm{~h}$ after transfection. Thereafter, $10 \mu \mathrm{l} \mathrm{CCK}$ solution and $100 \mu \mathrm{l}$ fresh medium were added to each well, and the plates were incubated in the dark at $37{ }^{\circ} \mathrm{C}$ for $2 \mathrm{~h}$. After incubation, the absorbance at $452 \mathrm{~nm}$ was measured using a Multiskan Go spectrometer (Thermo Fisher, USA). 
Table 1 Antibodies

\begin{tabular}{lllllll}
\hline Primary antibodies & Clonality & Catalogue number & Company & Species & Dilution & Diluent \\
\hline MMP2 & Monoclone & $66366-1-\mathrm{lg}$ & Proteintech & Mouse & $1: 1000$ & Non-fat milk \\
MMP9 & Monoclone & ab76003 & Abcam & Rabbit & $1: 500$ & Non-fat milk \\
BCl-2 & Monoclone & ab32124 & Abcam & Rabbit & $1: 1000$ & Non-fat milk \\
Caspase-3 & Monoclone & Ab32351 & Abcam & Rabbit & $1: 500$ & Non-fat milk \\
PD-L1 & Monoclone & Ab205961 & Abcam & Rabbit & $1: 500$ & Non-fat milk \\
GAPDH & Monoclone & $60004-1-\mathrm{lg}$ & Proteintech & Mouse & $1: 500$ & Non-fat milk \\
\hline
\end{tabular}

\section{Transwell invasion assay}

A total of $1 \times 10^{5}$ cells per well in triplicate were plated in the upper chamber of a 24-well plate (pore size $8 \mu \mathrm{m}$, Corning, USA) containing $200 \mu \mathrm{l}$ of serum-free MEM medium. For the invasion assay, the base of the upper chambers was coated with extracellular Matrigel (BD Biosciences, USA) to serve as a chemoattractant. Cells were allowed to invade for $24 \mathrm{~h}$. The Transwell chamber was then removed, the culture solution in the Transwell chamber was discarded, and the chamber was washed twice with calcium-free phosphate-buffered saline (PBS). After that, the chamber was fixed in methanol solution for $30 \mathrm{~min}$ and stained with $0.1 \%$ crystal violet for $20 \mathrm{~min}$ at room temperature. The chamber was washed several times with PBS, and the upper chamber liquid was aspirated. The unmigrated cells in the upper layer were gently wiped off using a cotton swab. The microporous membrane was removed carefully with small tweezers and dried with the bottom side up. Next, the membrane was transferred to a glass slide and sealed with neutral gum. Images were observed and collected by an inverted optical microscope (Keyence, Osaka, Japan).

\section{Annexin V/propidium iodide apoptosis assay}

Apoptosis assays were performed using a commercially available kit, per the manufacturer's protocol. HeLa cells (control), including the negative control (NC) and cells carrying TAZ siRNA, PD-L1 siRNA, or the TAZ plasmid, or cotransfected with the TAZ plasmid and PD-L1 siRNA were plated at $5 \times 10^{5} /$ well in each well of 6-well plates in duplicate. After $24 \mathrm{~h}$, the cells were harvested by trypsinization and suspended in PBS. The cells were subsequently suspended in $500 \mu \mathrm{l}$ binding buffer (BD Biosciences, USA). Later, $5 \mu \mathrm{l}$ annexin-V fluorescein isothiocyanate (FITC) (BD Biosciences, USA) and $5 \mu$ propidium iodide (PI) (both purchased from BD Biosciences, USA) were added, and the cells were incubated for $20 \mathrm{~min}$ in the dark. Finally, the samples were analyzed using flow cytometric analysis.

\section{Western blotting}

Antibodies against Bcl-2, Caspase-3, PD-L1, MMP-2 and MMP-9 were purchased from Abcam Group, Inc. The

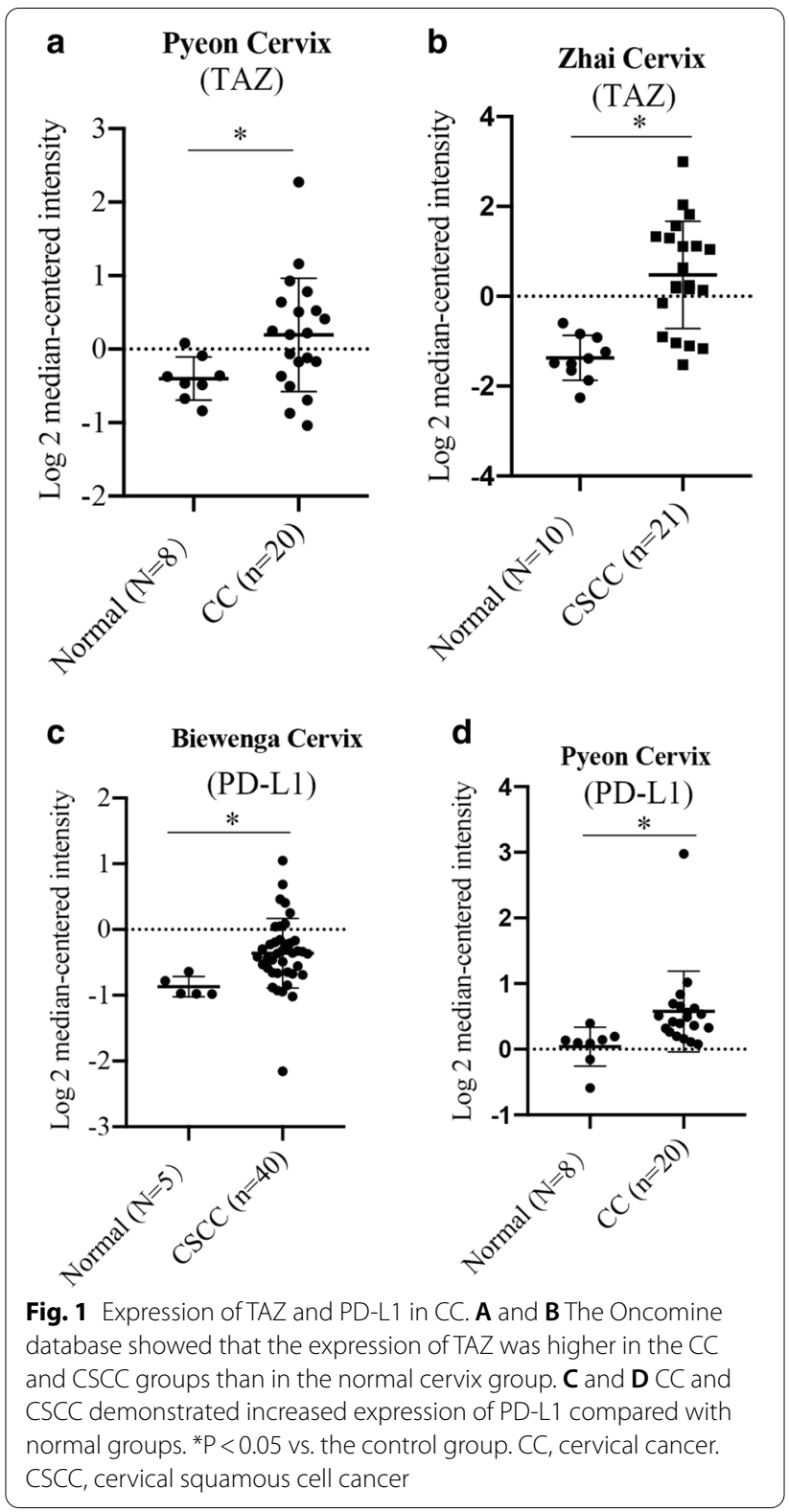



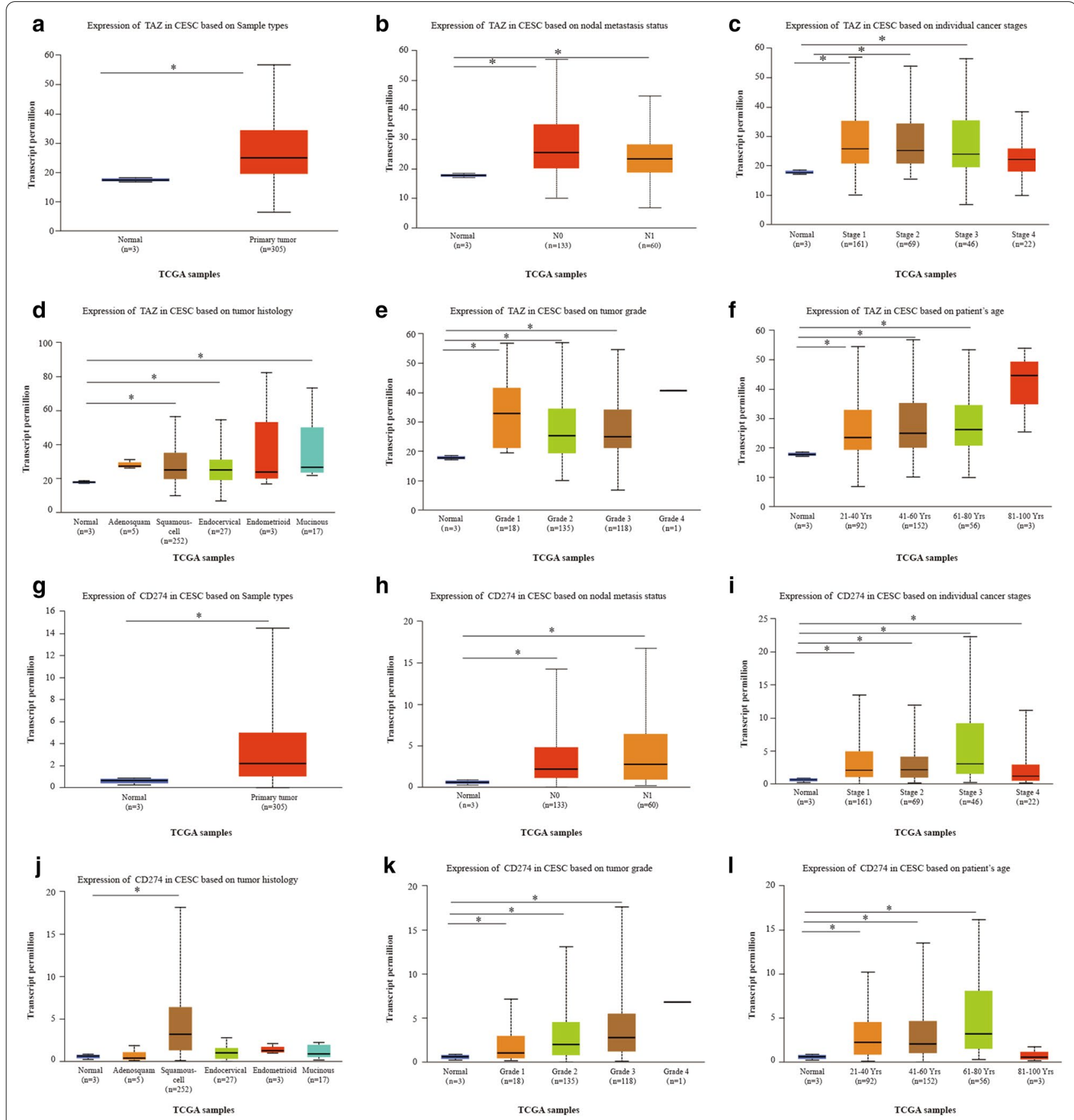

Fig. 2 Box plots evaluating TAZ and PD-L1 expression among different groups of patients based on clinical parameters using the UALCAN database. Analysis is shown for sample types $(\mathbf{A}$ and $\mathbf{G})$, metastasis $(\mathbf{B}$ and $\mathbf{H})$, cancer stage $(\mathbf{C}$ and $\mathbf{I})$, tumor histology $(\mathbf{D}$ and $\mathbf{J})$ tumor grade $(\mathbf{E}$ and $\mathbf{K})$ and age $(\mathbf{F}$ and $\mathbf{I})$. ${ }^{*} P<0.05$

information regarding the antibodies is summarized in Table 1 . The normal and transfected cells were scraped on ice, collected by centrifugation $(12,000 \times g, 10 \mathrm{~min}$, $4{ }^{\circ} \mathrm{C}$ ) for protein extraction, incubated with freshly prepared RIPA lysis buffer for $15 \mathrm{~min}$, and then quantified with a bicinchoninic acid (BCA) kit (Nanjing KeyGen
Biotech. Co., Ltd.). The protein sample was mixed with loading buffer and boiled for $8 \mathrm{~min}$. Subsequently, the sample was separated on a 10\% SDS-PAGE gel and electrotransferred onto PVDF membranes (Merck Millipore). The membranes were incubated for $1 \mathrm{~h}$ at room temperature with $5 \%$ fat-free milk in Tris-buffered saline 
containing Tween-20, followed by incubation overnight at $4{ }^{\circ} \mathrm{C}$ with primary antibodies. Protein bands were captured by a Li-Cor Odyssey Imaging system (LI-COR Biosciences, USA).

\section{Oncomine database analysis}

The expression levels of the TAZ and PD-L1 genes in cervical cancer were identified in the Oncomine database (https://www.oncomine.org/resource/login.html). The threshold was determined according to the following values: $P$ value $<0.05$.

\section{UALCAN}

UALCAN (http://ualcan.path.uab.edu/) is a web-based tool that provides in-depth analyses of transcriptome data from The Cancer Genome Atlas (TCGA) and MET500 data. UALCAN was used to investigate the expression of TAZ and PD-L1 and the association between TAZ and PD-L1 and various clinicopathological parameters of lung $\mathrm{CC}$.

\section{Gene expression profiling interactive analysis (GEPIA) and $\mathrm{R} 2$ database}

GEPIA (http://gepia.cancer-pku.cn/index.html) is a userfriendly web portal for gene expression analysis based on TCGA and GTEx data. The relationships between hepcidin and PD-1, PD-L1 and CTLA-4 were determined using Spearman's correlation coefficient in "correlation analysis". Additionally, to verify the correlation of TAZ and PD-L1 in patients with CC, an R2 database was used to analyze the relationship of TAZ and PD-L1.

\section{Tumor immune estimation resource (TIMER)}

TIMER (https://cistrome.shinyapps.io/timer/), an interactive web portal, performs comprehensive analysis on the infiltration levels of different immune cells. In the present study, TAZ expression in multiple types of cancer was evaluated through the "Diff Exp" module. The correlation of TAZ and immune cell infiltration in CC was analyzed in TIMER. The "Gene" module was used to investigate the relationship between TAZ expression and immune cell infiltration levels (B cells, CD8 + T cells, $\mathrm{CD} 4+\mathrm{T}$ cells, neutrophils, macrophages, and dendritic cells) using the TCGA database.

\section{Statistic analysis}

All statistical analyses were completed by using SPSS Inc. (Chicago, IL, USA). The Results are presented as the mean \pm standard deviation (SD) or standard error of the mean. Statistical significance was determined using ANOVA analysis followed by Tukey's post hoc test. The Spearman rank order correlation was used for the pairwise correlation analyses of expression between proteins. $\mathrm{P}<0.05$ was considered to indicate a statistically significant value.

\section{Result}

TAZ and PD-L1 are upregulated in CC

To observe the difference of expression of TAZ and PD-L1, a comprehensive analysis of hepcidin expression profiles was conducted using publicly assessable datasets from Oncomine database. The expression of TAZ mRNA was found to be increased in the CC group compared with the normal group (Fig. 1A and B). We also found that PD-L1 expression was higher in CC tissues from 2 different cohorts (Fig. 1C and D).
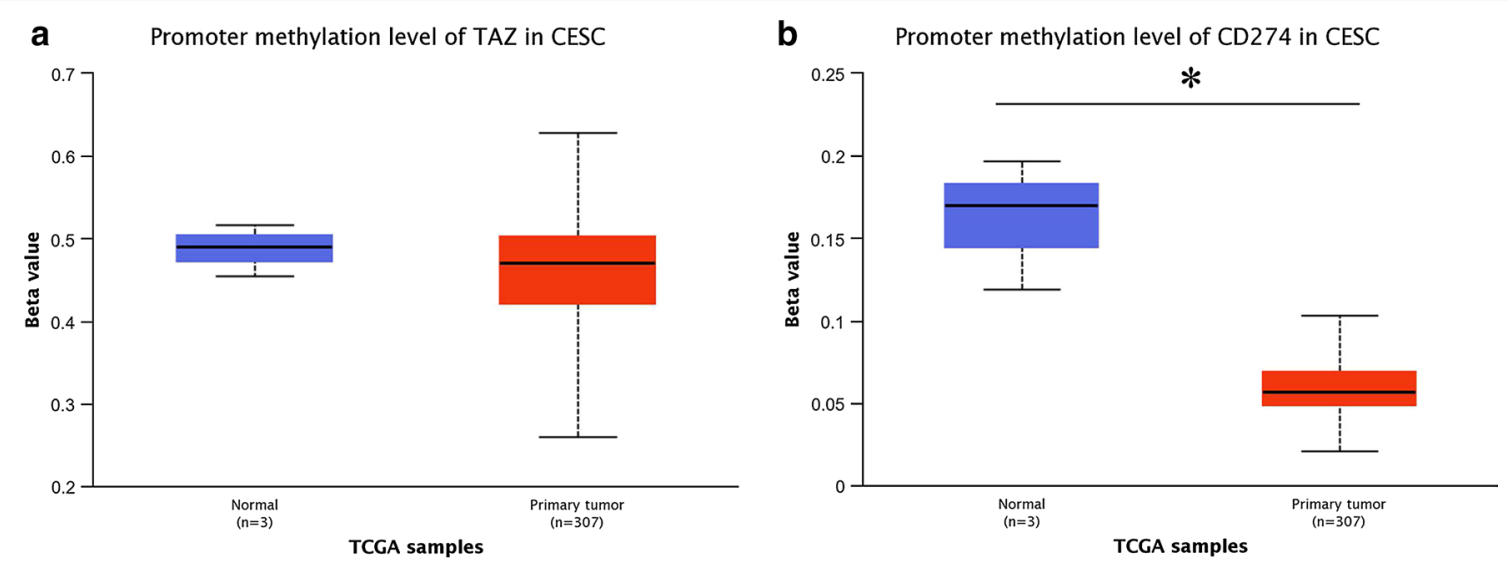

Fig. 3 The methylation of TAZ and PD-L1 on CC. A The UALCAN database showed that the level of methylation of TAZ was higher in the CC group than in the normal cervix group. B The PD-L1 methylation level was higher in the CC group than in the normal group. ${ }^{*} \mathrm{P}<0.05$ vs. the control group. CC, cervical cancer 

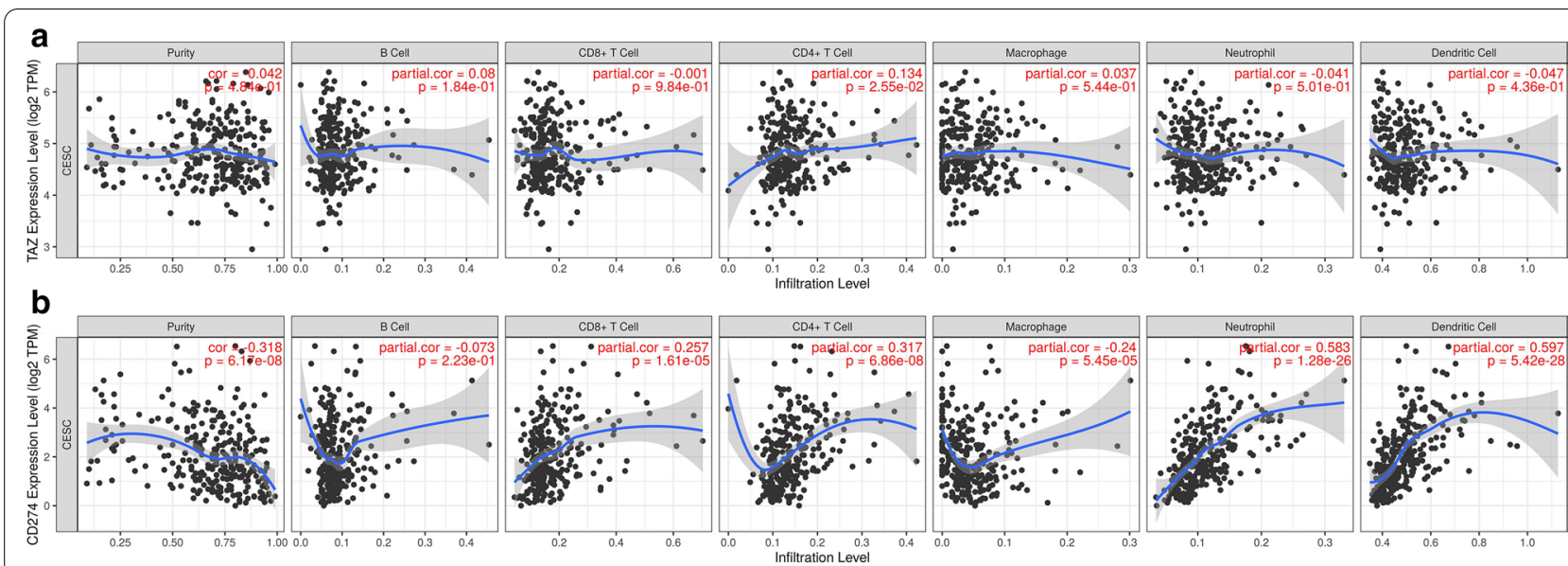

C

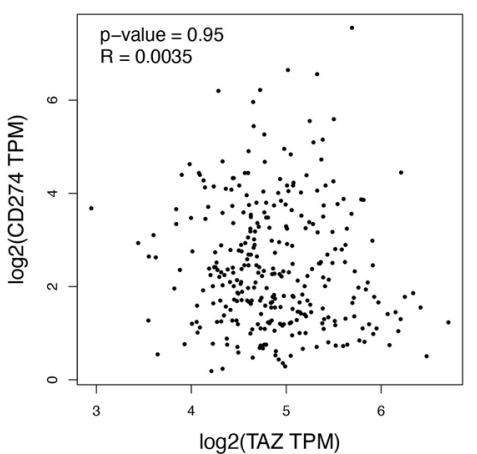

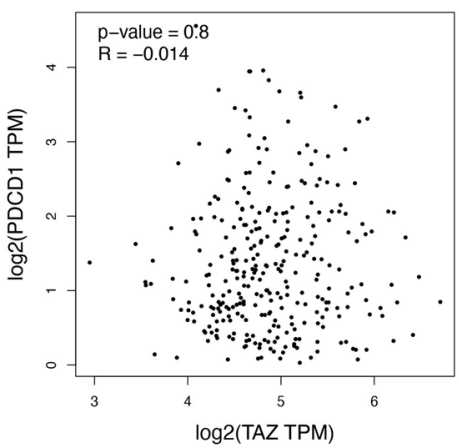

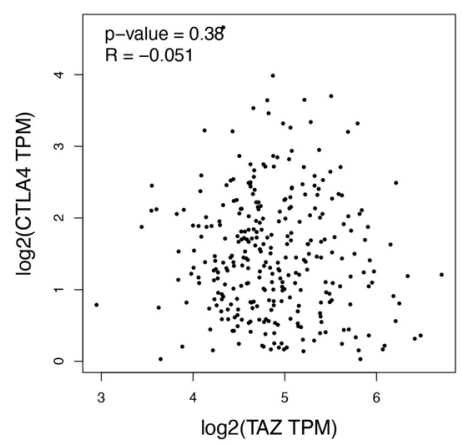

Fig. 4 Correlation of TAZ expression with immune infiltration level in CC. A TAZ expression is significantly negatively related to tumor purity and has significant positive correlations with infiltrating levels of CD4 +T cells in CC, other than CD8 +T cells, B cells, macrophages, neutrophils, and dendritic cells. B PD-L1 expression has significant positive correlations with infiltrating levels of CD4 + T cells in CC, CD8 + T cells, macrophages, neutrophils, and dendritic cells. C The GEPIA database indicated a positive correlation of TAZ and PD-L1 (CD274) and a negative association between TAZ and PD-1 (PDCD1) and CTLA4 in CC. *P $<0.05$. CC, cervical cancer

\section{Expression of TAZ and PD-L1 and clinical parameters of CC patients}

Considering of the high expression of TAZ and PD-L1, we then focused our investigation on $\mathrm{CC}$ and explored the clinical significance of TAZ and PD-L1 expression related to patient survival and disease progression. By using the UALCAN online tool, we then investigated TAZ and PD-L1 expression among groups of patients according to different clinical parameters. The expression of TAZ and PD-L1 was increased in Cervical squamous cell carcinoma and endocervical adenocarcinoma.

(CESCs) compared with normal controls (Fig. 2A and G). According to metastasis status, TAZ and PD-L1 expression were significantly upregulated in CESC samples classified as $\mathrm{N} 0$ and $\mathrm{N} 1$ compared to the corresponding normal controls; however, the expression of TAZ was lower in patients classified as N1 than in patients classified as No (Fig. 2B and $\mathrm{H}$ ). Regarding tumor stage, a significant increase in TAZ expression was observed in CESC patients in stages $1,2,3$, and 4, and a significantly increased expression of PD-L1 was observed in CESE patients in stages 1, 2, and 3 (Fig. 2C and I). Based on tumor histology, TAZ expression was higher in patients with squamous, endocervical, and mucinous cell types (Fig. 2D). PD-L1 expression was higher in the squamous cell type of CESC (Fig. 2J). Upregulation of TAZ and PD-L1 expression was observed in the grade 1, 2, and 3 CESC groups compared to the normal controls (Fig. 2E and $\mathrm{K}$ ). In terms of age, the TAZ level was significantly elevated in CESC patients from different age groups (2140 years, $41-60$ years, $61-80$ years) (Fig. $2 F$ ). In addition, PD-L1 expression was dramatically increased in CESC patients aged $21-40$ years, $41-60$ years, and $61-80$ years (Fig. 2L). These results suggest that there is a significant correlation between the expression of TAZ and PD-L1 and the clinical parameters of CESC patients.

\section{Methylation of TAZ and PD-L1 in CC patients}

We used the UALCAN database to observe the methylation levels of TAZ and PD-L1. The methylation levels of the TAZ promoter tended to be higher in normal controls than in CESC patients (Fig. 3A). Similarly, 


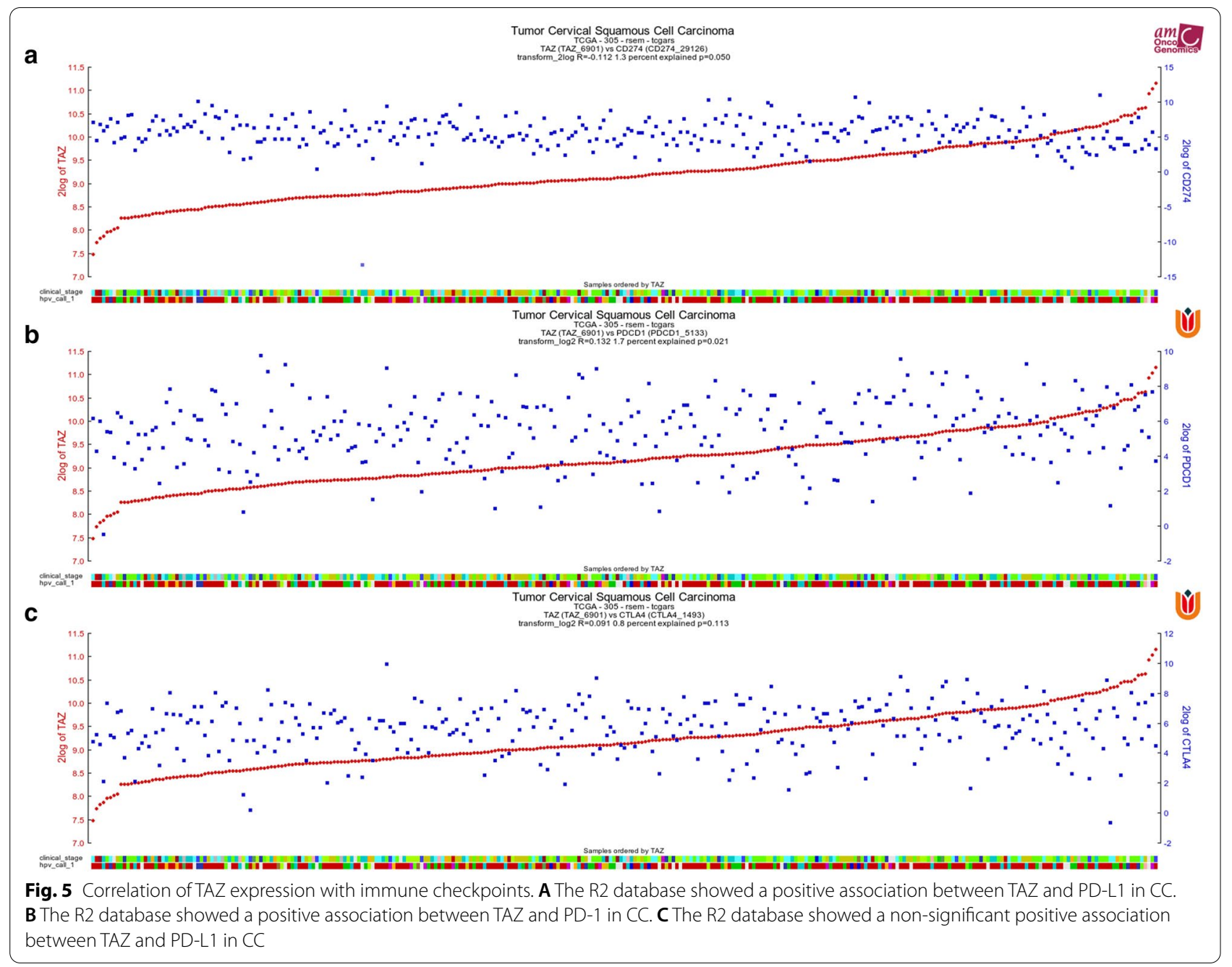

PD-L1 promoter methylation levels were dramatically higher in the normal controls than in the CESC groups (Fig. 3B). These results indirectly demonstrated that the CESC groups showed higher expression of TAZ and PD-L1.

\section{Correlation analysis between TAZ expression and infiltrating immune cells}

To further assess the effect of TAZ and PD-L1 on the tumor microenvironment (TME), we estimated the correlation between TAZ and PD-L1 and immune cells by using the TIMER database. We analyzed the correlation between TAZ expression and B cells, CD4+ T cells, CD8 $+\mathrm{T}$ cells, neutrophils, macrophages, and dendritic cells. The results showed that there was a significant positive relationship between TAZ expression levels and the infiltration of CD4 $+\mathrm{T}$ cells, and there were no significant correlations between the levels of TAZ and B cells, CD8 + T cells, macrophages, neutrophils, and dendritic cells in CESCs (Fig. 4A). We also analyzed the relationship between PD-L1 expression and B cells, CD4 + T cells, CD8 + T cells, neutrophils, macrophages, and dendritic cells. The result demonstrated that the expression of PD-L1 was associated with $\mathrm{CD} 4+\mathrm{T}$, cells $\mathrm{CD} 8+\mathrm{T}$ cells, macrophages, neutrophils, and dendritic cells in CESCs, but was not correlated with B cells (Fig. 4B).

\section{Correlation analysis between TAZ expression and immune checkpoints}

Based on high expression of TAZ and PD-L1, the significant association between $\mathrm{CD} 4+\mathrm{T}$ cells and the expression of TAZ and PD-L1 in CC, we also want to know whether there is a significant correlation between TAZ and PD-L1. We found that TAZ expression was positively correlated with PD-L1 and PD-1 expression by utilizing 

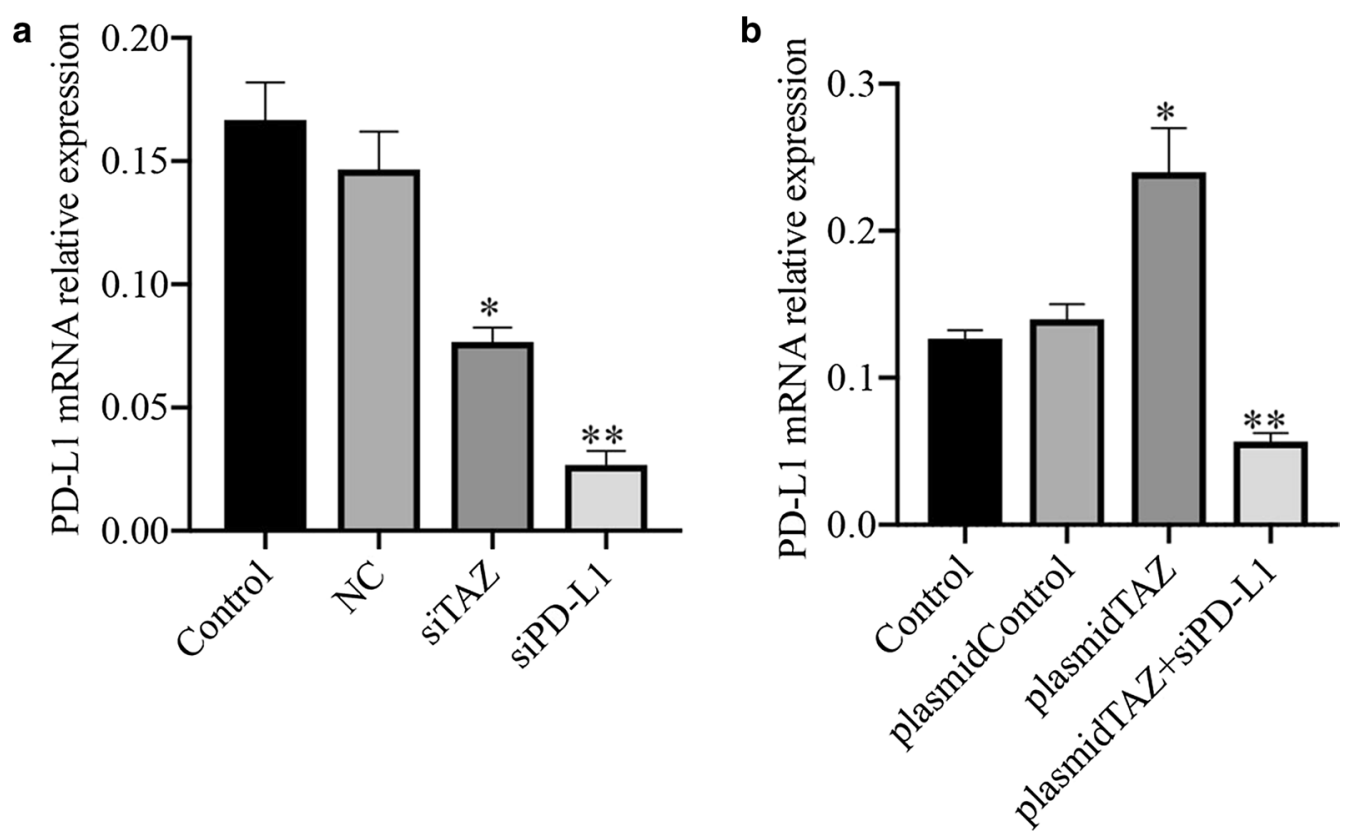

Fig. 6 The expression of PD-L1 mRNA in CC. A The level of PD-L1 mRNA was lower in the TAZ siRNA and PD-L1 siRNA groups than in the control groups. B PD-L1 expression was upregulated in the TAZ plasmid groups compared with the control groups, and PD-L1 expression was decreased in the TAZ plasmid and PD-L1 siRNA groups compared with the TAZ plasmid groups. ${ }^{*} \mathrm{P}<0.05$. CC, cervical cancer

the R2 database. However, there is no significant correlation between TAZ and CTLA4 expression via R2 database (Fig. 5A-C). Additionally, we also used the GEPIA database to investigate the correlation between TAZ expression and immune checkpoints (PD-L1, PD-1, and CTLA4). We found that TAZ expression was positively associated with PD-L1; however, it was negatively correlated with PD-1 and CTLA4 (Fig. 4C).

\section{PD-L1 is upregulated by TAZ in CC cells}

Given the positive correlation between TAZ and PD-L1, we want to know whether PD-L1 can be regulated by TAZ. We transfected TAZ siRNA into HeLa cells. PD-L1 was significantly decreased by TAZ siRNA at the mRNA level, as shown by qRT-PCR, in contrast with the normal and negative control groups (Fig. 6A). When we transfected TAZ plasmid into HeLa cells, the level of PD-L1 mRNA was upregulated compared with the normal and negative control groups (Fig. 6B). Furthermore, when we transfected TAZ plasmid and PD-L1 siRNA into CC cells, the mRNA level of PD-L1 was downregulated compared with that in the TAZ plasmid groups (Fig. 6B). Similarly, the protein expression of PD-L1 was inhibited in groups of TAZ siRNA and PD-L1 siRNA compared with normal control groups (Fig. 7A). In addition, the expression of PD-L1 was downregulated in groups of TAZ plasmid and PD-L1 siRNA compared with that in the TAZ plasmid groups (Fig. 7B).
TAZ improves cell proliferation of CC Cells via upregulating PD-L1

Previous studies have shown that TAZ can make an important role on $C C$, and we also found there is a positive correlation between TAZ and PD-L1. Therefore, we next evaluated whether TAZ can regulate the characteristics of cancer cells via PD-L1.

To determine the influence of TAZ on CC cells, we used a CCK-8 assay to assess cell proliferative capacity. There was a decrease in cell proliferation in the TAZ siRNA and PD-L1 siRNA groups compared with the control and negative control groups (Fig. 8A, $\mathrm{P}<0.05$ ). The cell groups transfected with the TAZ plasmid showed higher cell growth ability than the control and negative groups (Fig. 8B, $\mathrm{P}<0.05)$. The cell proliferation capacity in the TAZ plasmid and PD-L1 siRNA cell groups was decreased compared with that in the TAZ plasmid group (Fig. 8B, $\mathrm{P}<0.05$ ).

\section{TAZ improves cell invasion of CC cells via upregulating} PD-L1

The invasion ability of the cell groups transfected with TAZ siRNA and PD-L1 siRNA was weakened compared with that of the control and negative groups (Fig. 8C, $\mathrm{P}<0.05$ ) according to the Transwell assay. There was an increase in cell invasion ability in the TAZ plasmid groups, even if the statistical analysis was not significant (Fig. 8D). In addition, the groups transfected with the TAZ plasmid and PD-L1 siRNA showed lower invasion capacity than the groups 


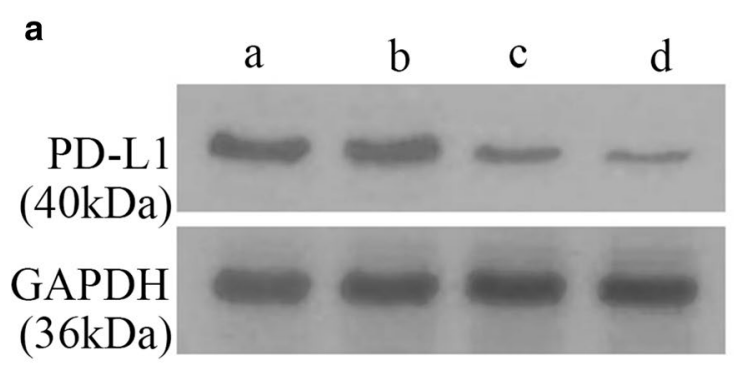

a. Control

b. NC

c. siTAZ

d. siPD-L1

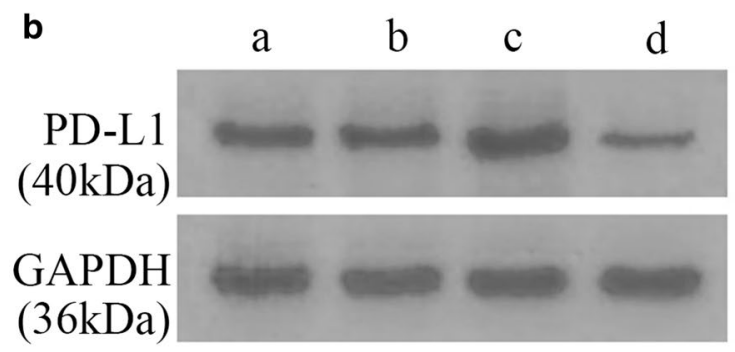

a. Control

b. PlasmidNC

\section{c. PlasmidTAZ}
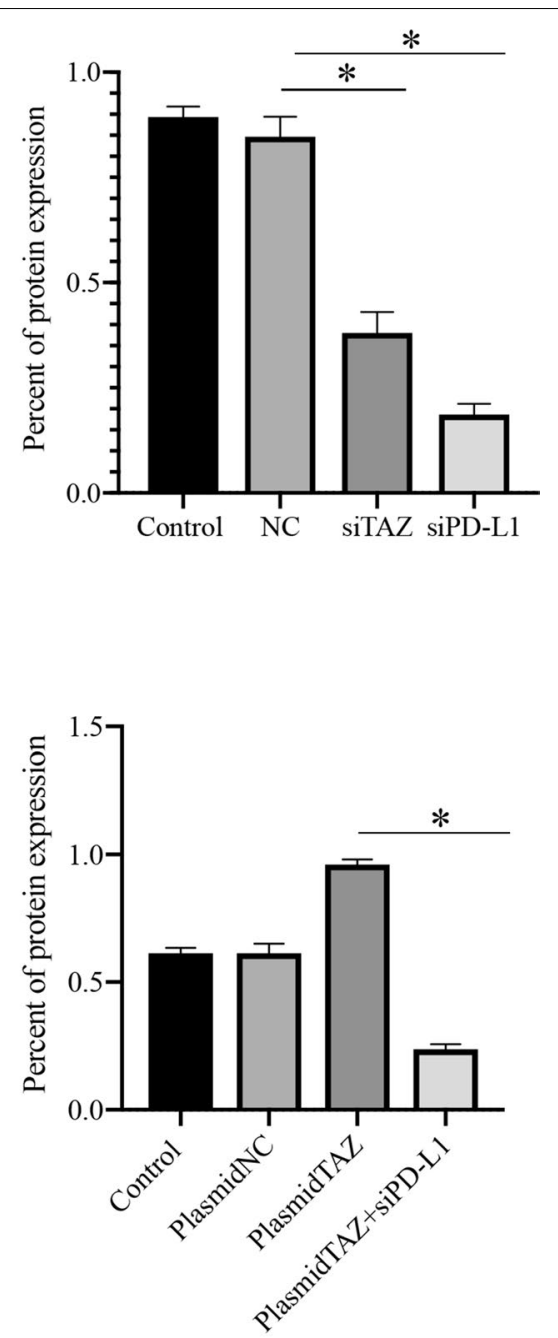

\section{d. PlasmidTAZ+siPD-L1}

Fig. 7 The protein expression of PD-L1 in CC. A The level of PD-L1 was lower in the TAZ siRNA and PD-L1 siRNA groups than in the control groups. B PD-L1 expression was upregulated in the TAZ plasmid groups compared with the control groups, and PD-L1 expression was decreased in the TAZ plasmid and PD-L1 siRNA groups compared with the TAZ plasmid groups. ${ }^{*} \mathrm{P}<0.05$. CC, cervical cancer

transfected with only the TAZ plasmid (Fig. 8D, $\mathrm{P}<0.05$ ). Additionally, the protein expression of MMP-2 and MMP-9 in was decreased in groups of TAZ siRNA and PD-L1 siRNA compared with that of the control and negative groups (Fig. 9A, $\mathrm{P}<0.05)$. the groups transfected with the TAZ plasmid and PD-L1 siRNA showed lower expression of PD-L1 than the groups transfected with only the TAZ plasmid (Fig. 9B, $\mathrm{P}<0.05$ ).

\section{TAZ inhibits cell apoptosis of CC cells via upregulating PD-L1}

The present study further assessed whether TAZ could inhibit apoptosis in CC by regulating PD-L1. An annexin V/PI apoptosis assay was performed using flow cytometry. The percentages of apoptosis in the groups transfected with TAZ siRNA and PD-L1 siRNA were $16.9 \%$ and $26.1 \%$, respectively, which were higher than those in the control groups (Fig. 10A, $\mathrm{P}<0.05$ ). The percent of apoptosis in the groups transfected with the TAZ plasmid was $0.6 \%$, which was lower than that in the control groups (Fig. 10B, $\mathrm{P}<0.05$ ). Additionally, when we transfected TAZ plasmid and PD-L1 siRNA into the cell groups, the percent of apoptosis was increased compared with that in the TAZ plasmid groups (Fig. 10B, $\mathrm{P}<0.05$ ).

The study also evaluated the expression of $\mathrm{Bcl}-2$ and Caspase-3, and the expression of Bcl-2 in groups 


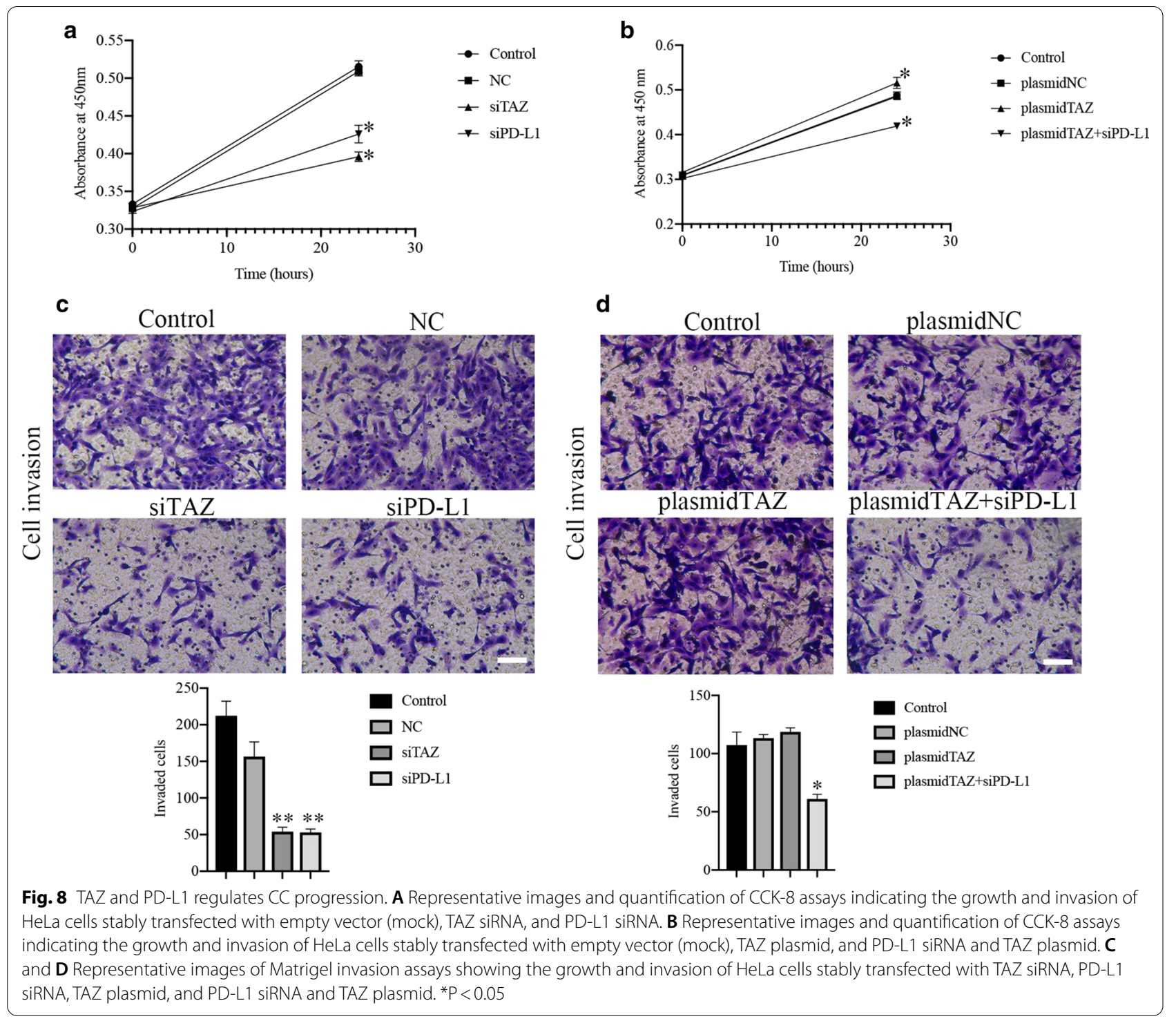

transfected with TAZ plasmid and PD-L1 siRNA was decreased compared with that in the TAZ plasmid groups (Fig. 10C). In contrast, the expression of Caspase-3 was increased in the TAZ plasmid and PD-L1 siRNA groups compared with that in the TAZ plasmid group (Fig. 10C).

\section{Discussion}

$\mathrm{CC}$ is considered a common gynecological cancer in women worldwide, with 570,000 reported incident cases documented each year [19]. Therefore, it is of utmost importance to identify novel treatment strategies for CC.

Here, we have defined TAZ, a Hippo signaling transducer and a novel oncogene, as being responsible for CC tumorigenesis. Our data revealed that TAZ is significantly overexpressed in $\mathrm{CC}$ and is closely correlated with PD-L1. Notably, TAZ promotes proliferation, anti-apoptosis, migration, and invasion by regulating PD-L1 in CC. We indicated a novel mechanism of TAZ in $\mathrm{CC}$, which is extremely important for the treatment of CC.

Cancer research in the past decade has indicated that the Hippo pathway regulates cell proliferation, tissue homeostasis, and organ size and is a promoter of tumorigenesis and tumor migration [20,21]. As a paralog of YAP, TAZ shares $46 \%$ homology with YAP. In numerous studies, both YAP and TAZ are referred to as a pair, as many antibodies detect both proteins due to their high similarity. Importantly, YAP and TAZ cannot 


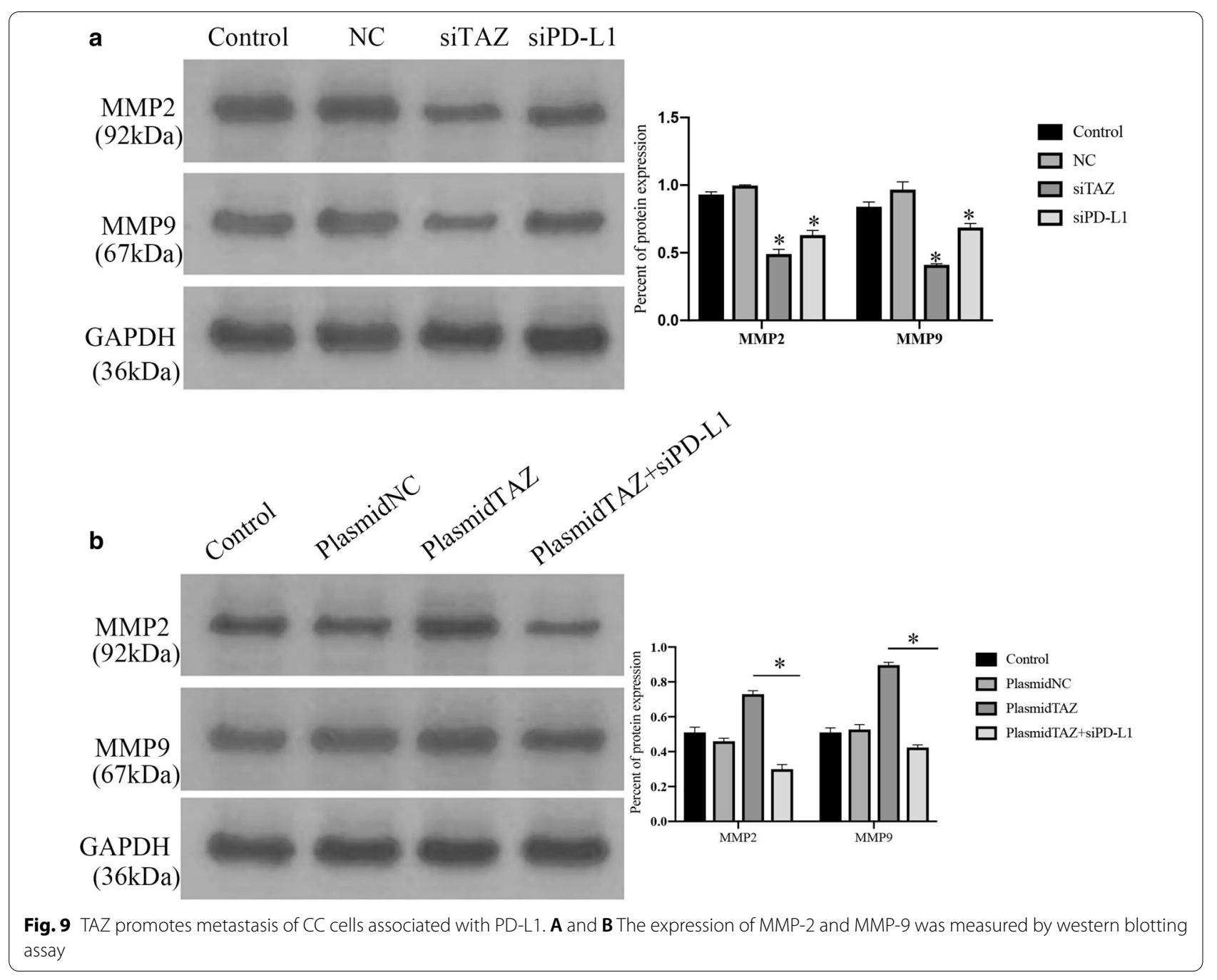

compensate for each other [22]. Previous studies found that active TAZ increased migration and colony forming ability but had no effect on proliferation. This result was associated with increased expression of E-cadherin, FN1, vimentin, and B-catenin [23]. TAZ can function independently of YAP to enhance DNA synthesis and appears to be important in cell cycle regulation [24]. A previous study analyzed the function of the Hippo pathway in 308 CC patients from The Cancer Genome Atlas (TCGA) and showed that TAZ was continually amplified in CC, and the high genetic expression of TAZ was associated with poor prognosis [12]. In recent years, several tumors, including thyroid carcinoma [25], rectal cancer [26], and colon cancer [27], have shown high levels of TAZ, suggesting that it may function as a promoter in tumorigenesis. Similarly, we also found that TAZ is overexpressed in $\mathrm{CC}$ and can induce growth and metastasis and inhibit apoptosis of CC cells.
How does TAZ affect tumorigenesis and tumor migration? A recent study found that the overexpression of several genes in the JAK-STAT3 pathway is induced by active YAP1 and TAZ interacting with the transcription factor TEAD [28]. This pathway controls the response to inflammatory cytokines, is present at high levels in pancreatic tumors, and can lead to PanIN progression in $\operatorname{KRas}^{G 12 D}$ mice $[29,30]$. In addition, TAZ is necessary for TGF- $\beta$ response elements and maintains the nuclear accumulation of the Smad2/3Smad4 complex and stem cell self-renewal mediated by TGF- $\beta$ [31]. Noticeably, YAP and TAZ can have a positive effect on the expression of the immune checkpoint molecule PD-L1, thereby suppressing the antitumor ability of $\mathrm{T}$ cells in several different models [32]. Feng et al. demonstrated that the $\mathrm{pH}$ of the extracellular environment can affect the activity of Hippo signaling in human lung adenocarcinoma, which induces TAZ to upregulate the level of PD-L1 [33]. PD-L1 or B7-H1 is 

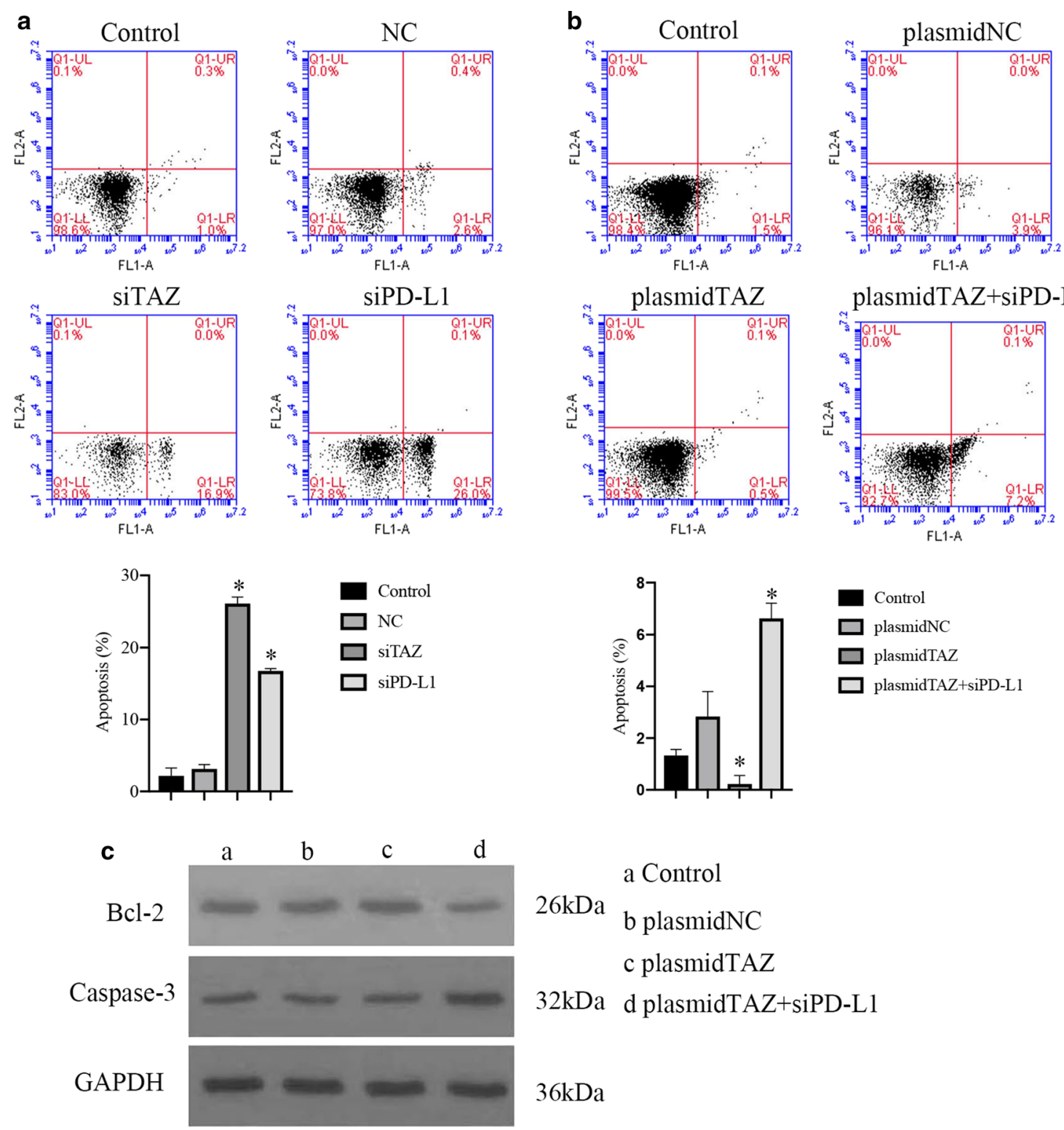

Fig. 10 TAZ suppresses apoptosis of CC cells associated with PD-L1. A Apoptosis was induced in TAZ siRNA cell group and PD-L1 siRNA cell groups Compared with control cell group. B Apoptosis was inhibited in plasmidTAZ cell group Compared with control cell group. Apoptosis was induced in plasmidTAZ and siPD-L1 groups Compared with plasmid TAZ cell group, $\mathrm{P}<0.05$. C The expression of $\mathrm{BCl}-2$ and Caspase-3 was measured by western blotting assay

the major ligand for PD-1 [34]. PD-L1 is expressed in immune cells, including activated T cells, B cells, dendritic cells, macrophages, and various tumor cells [35, 36]. Normally, PD-L1 expression maintains the homeostasis of the immune response. PD-L1 expressed by cancer cells and infiltrating immune cells can bind to PD-1 on $\mathrm{T}$ cells and then suppress the functions of $\mathrm{T}$ cells in the tumor microenvironment [37, 38]. Prognosis determined by oncological histology is closely related to the expression of $\mathrm{PD}-\mathrm{L} 1$; therefore, intervention in $\mathrm{PD}-\mathrm{L} 1$ expression can be the key to tumor therapy [39-42]. Multiple studies identified PD-L1 as a direct transcriptional target of YAP/TAZ/TEAD and showed that YAP and/or TAZ activation upregulates PD-L1 in human breast cancer, NSCLC, mesothelioma and melanoma cells [43]. We characterized the molecular mechanisms by which TAZ enhances PD-L1 
expression by binding to the PD-L1 promoter through the TEAD family of transcription factors.

Recent data suggested that PD-L1 is overexpressed in $\mathrm{CC}$ cells and can promote the growth and metastasis of CC [44]. PD-L1 is an important biomarker for evaluating $\mathrm{CC}$ prognosis and clinical pathological characteristics [45]. Consistent with this, our results also showed that TAZ expression is significantly correlated with PD-L1 expression in CC, and TAZ inhibited the percent apoptosis of cervical cancer cells by regulating PD-L1 and promoted proliferation and metastasis.

Research developments have led to an entirely new class of drugs, antibodies directed against PD-L1/PD-1, which promote the body's immune system to fight cancer. The expression and roles of TAZ and PD-L1 in the progression of $\mathrm{CC}$ provide great potential for observing new targeted cancer therapies.

\section{Acknowledgements}

We apologize to the many authors whose studies are important but could not be cited due to space limitation. We thank for all authors who kindly give discussion and suggestion for this study.

\section{Authors' contributions}

YH conceived and managed the project. YH and DL wrote the manuscript. LL revised the paper. All authors read and approved the final manuscript.

\section{Funding}

No funding.

\section{Availability of data and materials}

All data generated or analysed during this study are included in this published article.

\section{Declarations}

Ethics approval and consent to participate

Not applicable.

\section{Consent for publication}

Not applicable.

\section{Competing interests}

The authors declare no conflict of interest.

\section{Author details}

${ }^{1}$ Department of Pathology, Okayama University Graduate School of Medicine, Dentistry, and Pharmaceutical Sciences, 2-5-1, Shikata-cho, Kita-ku, Okayama 700-8558, Japan. ${ }^{2}$ The Fourth Medical Center of The General Hospital of the Chinese People's Liberation Army, Beijing 100048, China. ${ }^{3}$ Pathology Department of Dalian Medical University, Liaoning 116044, China.

Received: 24 June 2021 Accepted: 20 October 2021

Published online: 04 November 2021

\author{
References \\ 1. Siegel RL, Miller KD, Jemal A. Cancer statistics, 2015. CA Cancer J Clin. \\ 2015;65:5-29.
}

2. Zhang Z, Chen F, Li S, Guo H, Xi H, Deng J, et al. ERG the modulates Warburg effect and tumor progression in cervical cancer. Biochem Biophys Res Commun. 2020:522:191-7.

3. Pan D. The Hippo signaling pathway in development and cancer. Dev Cell. 2010;19:491-505.

4. Dong J, Feldmann G, Huang J, Wu S, Zhang N, Comerford SA, et al. Elucidation of a universal size-control mechanism in Drosophila and mammals. Cell. 2007;130:1120-33.

5. Zhao B, Wei X, Li W. Inactivation of YAP oncoprotein by the Hippo pathway is involved in cell contact inhibition and tissue growth control. Genes Dev. 2007;21:2747-61.

6. Wang D, He J, Dong J, Meyer TF, Xu T. The HIPPO pathway in gynecological malignancies. Am J Cancer Res. 2020;10:610-29.

7. Cordenonsi M, Zanconato F, Azzolin L, Forcato M, Rosato A, Frasson C, et al. The Hippo transducer TAZ confers cancer stem cell-related traits on breast cancer cells. Cell. 2011;147:759-72.

8. Chan SW, Lim CJ, Guo K. A role for TAZ in migration, invasion, and tumorigenesis of breast cancer cells. Cancer Res. 2008;68:2592-8.

9. Piccolo S, Cordenonsi M, Dupont S. Molecular pathways: YAP and TAZ take center stage in organ growth and tumori-genesis. Clin Cancer Res. 2013;19:4925-30.

10. Guo L, Teng L. YAP/TAZ for cancer therapy: opportunities and challenges (review). Int J Oncol. 2015;46:1444-52.

11. Buglioni S, Vici P, Sergi D, Pizzuti L, Di Lauro L, Antoniani B, et al. Analysis of the hippo transducers TAZ and YAP in cervical cancer and its microenvironment. Oncoimmunology. 2016;5: e1160187.

12 Cancer Genome Atlas Research Network. Integrated genomic and molecular characterization of cervical cancer. Nature. 2017;543:378-84.

13. Wang $X$, Teng F, Kong L, Yu J. PD-L1 expression in human cancers and its association with clinical outcomes. Onco Targets Ther. 2016:9:5023-39.

14. Mezache L, Paniccia B, Nyinawabera A, Nuovo GJ. Enhanced expression of PD L1 in cervical intraepithelial neoplasia and cervical cancers. Mod Pathol. 2015;28:1594-602.

15. Li J, Chen L, Xiong Y, Zheng X, Xie Q, Zhou Q, et al. Knock- down of PD-L1 in human gastric cancer cells inhibits tumor progression and improves the cytotoxic sensitivity to CIK therapy. Cell Physiol Biochem. 2017:41:907-20

16. Guo $X$, Zhao $Y$, Yan $H$, Yang $Y$, Shen $S$, Dai $X$, et al. Single tumor-initiating cells evade immune clearance by recruiting type II macrophages. Genes Dev. 2017;31:247-59.

17. Murakami S, Shahbazian D, Surana R, Zhang W, Chen H, Graham GT, et al. Yes-associated protein mediates immune reprogramming in pancreatic ductal adenocarcinoma. Oncogene. 2017;36:1232-44.

18. van Rensburg HJJ, Azad T, Ling M, Hao Y, Snetsinger B, Khanal P, et al. The hippo pathway component TAZ promotes immune evasion in human cancer through PD-L1. Cancer Res. 2018;15:1457-70.

19. Bray F, Ferlay J, Soerjomataram I, Siegel RL, Torre LA, Jemal A. Global cancer statistics 2018: GLOBOCAN estimates of incidence and mortality worldwide for 36 cancers in 185 countries. CA Cancer J Clin. 2018:68:394-424.

20. Pfleger CM. The Hippo Pathway: a master regulatory network important in development and dysregulated in disease. Curr Top Dev Biol. 2017;123:181-228.

21 Zanconato F, Cordenonsi M, Piccolo S. YAP/TAZ at the roots of cancer. Cancer Cell. 2016;29:783-803.

22 Coffey K. Targeting the Hippo pathway in prostate cancer: what's new? Cancers. 2021. https://doi.org/10.3390/cancers13040611.

23. Liu CY, Yu T, Huang Y, Cui L, Hong W. ETS (E26 transformation-specific) upregulation of the transcriptional co-activator TAZ promotes cell migration and metastasis in prostate cancer. J Biol Chem. 2017;292:9420-30.

24. Lee HJ, Ewere A, Diaz MF, Wenzel PL. TAZ responds to fluid shear stress to regulate the cell cycle. Cell Cycle. 2018;17:147-53.

25. Zhang S, Zhang J, Evert K, Li X, Liu P, Kiss A, et al. The hippo effector transcriptional coactivator with PDZ-binding motif cooperates with oncogenic beta-catenin to induce hepatoblastoma development in mice and humans. Am J Pathol. 2020;190:1397-413. 
26. Pathak S, Meng WJ, Zhang H, Gnosa S, Nandy SK, Adell G, et al. Tafazzin protein expression is associated with tumorigenesis and radiation response in rectal cancer: a study of Swedish clinical trial on preoperative radiotherapy. PLoS ONE. 2014;9: e98317.

27. Hageman JH, Heinz MC, Kretzschmar K, van der Vaart J, Clevers H, Snippert HJG. Intestinal regeneration: regulation by the microenvironment. Dev Cell. 2020;54:435-46.

28. Gruber R, Panayiotou R, Nye E, Spencer-Dene B, Stamp G, Behrens A. YAP1 and TAZ control pancreatic cancer initiation in mice by direct up-regulation of JAK-STAT3 signaling. Gastroenterology. 2016;151:526-39.

29. Nagathihalli NS, Castellanos JA, VanSaun MN, Dai X, Ambrose M, Guo Q et al. Pancreatic stellate cell secreted IL-6 stimulates STAT3 dependent invasiveness of pancreatic intraepithelial neoplasia and cancer cells. Oncotarget. 2016;7:65982-92.

30. Lesina M, Kurkowski MU, Ludes K. Stat3/Socs3 activation by IL-6 transsignaling promotes progression of pancreatic intraepithelial neoplasia and development of pancreatic cancer. Cancer Cell. 2011;19:456-69.

31. Chen YA, Lu CY, Cheng TY, Pan SH, Chen HF, Chang NS. WW domaincontaining proteins YAP and TAZ in the hippo pathway as key regulators in stemness maintenance, tissue homeostasis, and tumorigenesis. Front Oncol. 2019;11(9):60.

32. Yang H, Hall SRR, Sun B, Zhao L, Gao Y, Schmid RA, et al. NF2 and canonical hippo-YAP pathway define distinct tumor subsets characterized by different immune deficiency and treatment implications in human pleural mesothelioma. Cancers. 2021. https://doi.org/10.3390/cancers130 71561.

33. Feng J, Yang $H$, Zhang $Y$, Wei $H$, Zhu Z, Zhu B, et al. Tumor cell-derived lactate induces TAZ-dependent upregulation of PD-L1 through GPR81 in human lung cancer cells. Oncogene. 2017;19:5829-39.

34. Ai L, Xu A, Xu J. Roles of PD-1/PD-L1 pathway: signaling, cancer, and beyond. Adv Exp Med Biol. 2020;1248:33-59.

35. de Sa RS, Galvis MM, Mariz B, Leite AA, Schultz L, Almeida OP, et al. Increased tumor immune microenvironment CD3+ and CD20+ lymphocytes predict a better prognosis in oral tongue squamous cell carcinoma. Front Cell Dev Biol. 2020;8: 622161.

36 Zhang W, Liu Y, Yan Z, Yang H, Sun W, Yao Y, et al. IL-6 promotes PD-L1 expression in monocytes and macrophages by decreasing protein tyrosine phosphatase receptor type $\mathrm{O}$ expression in human hepatocelIular carcinoma. J Immunother Cancer. 2020. https://doi.org/10.1136/ jitc-2019-000285.

37. Wang PF, Chen Y, Song SY, Wang TJ, Ji WJ, Li SW, et al. Immune-related adverse events associated with anti-PD-1/PD-L1 treatment for malignancies: a meta-analysis. Front Pharmacol. 2017:8:730.

38. Gu X, Dong M, Liu Z, Mi Y, Yang J, Zhang Z, et al. Elevated PD-L1 expression predicts poor survival outcomes in patients with cervical cancer. Cancer Cell Int. 2019;19:146.

39. Lilja-Fischer JK, Eriksen JG, Georgsen JB. Prognostic impact of PD-L1 in oropharyngeal cancer after primary curative radiotherapy and relation to HPV and tobacco smoking. Acta Oncol. 2020;59(6):666-72.

40. Zhang F, Gong W. Prognostic and clinicopathological utility of programmed death-ligand 1 in malignant pleural mesothelioma: a metaanalysis. Int Immunopharmacol. 2020;83: 106481.

41. Giatromanolaki A, Koukourakis IM, Balaska K, Mitrakas AG, Harris AL, Koukourakis MI. Programmed death-1 receptor (PD-1) and PD-ligand-1 (PD-L1) expression in non-small cell lung cancer and the immune-suppressive effect of anaerobic glycolysis. Med Oncol. 2019;36:76.

42. Wang C, Weng M, Xia S, Zhang M, Chen C, Tang J, et al. Distinct roles of programmed death ligand 1 alternative splicing isoforms in colorectal cancer. Cancer Sci. 2021;112:178-93.

43. Nguyen CDK, Yi C. YAP/TAZ signaling and resistance to cancer therapy. Trends Cancer. 2019;5(5):283-96.

44. Dong P, Xiong Y, Yu J, Chen L, Tao T, Yi S, et al. Control of PD-L1 expression by miR-140/142/340/383 and oncogenic activation of the OCT4-miR-18a pathway in cervical cancer. Oncogene. 2018;37:5257-68.

45. Feng $M, X u L, H e Y$, Sun $L$, Zhang Y, Wang W. Clinical significance of PD-L1 (CD274) enhanced expression in cervical squamous cell carcinoma. Int J Clin Exp Pathol. 2018;11:5370-8.

\section{Publisher's Note}

Springer Nature remains neutral with regard to jurisdictional claims in published maps and institutional affiliations.
Ready to submit your research? Choose BMC and benefit from:

- fast, convenient online submission

- thorough peer review by experienced researchers in your field

- rapid publication on acceptance

- support for research data, including large and complex data types

- gold Open Access which fosters wider collaboration and increased citations

- maximum visibility for your research: over $100 \mathrm{M}$ website views per year

At BMC, research is always in progress.

Learn more biomedcentral.com/submissions 